
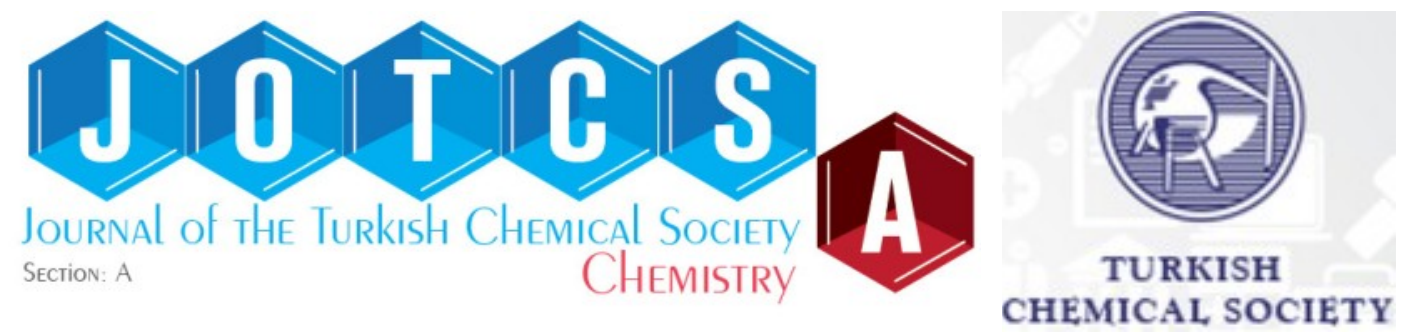

\title{
Adsorption of Methylene Blue and Methyl Orange from Aqueous Solution using Orange Peel and CTAB-Modified Orange Peel
}

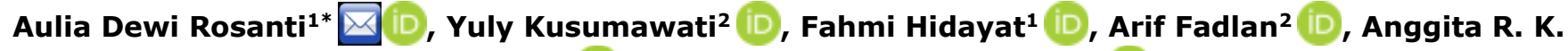 \\ Wardani $^{1}$ (D), Herlina Agusyanti Anggraeni ${ }^{1}$
}

${ }^{1}$ Universitas Islam Kadiri, Department of Chemistry, Kediri, 64128, Indonesia

${ }^{2}$ Institut Teknologi Sepuluh Nopember, Department of Chemistry, Surabaya, 60111, Indonesia

Abstract : Cationic and anionic dyes are frequently used in industrial sectors and cause many environmental and health problems. Orange peel has the potential to absorb dye as an adsorbent. This study aimed to explore the adsorption of methylene blue (MB) as a cationic dye and methyl orange (MO) as an anionic dye using orange peel (OP) and its modification using cetyltrimethylammonium bromide (CTAB). OP and OP-CTAB biomass materials were characterized using FT-IR (Fourier transform infrared), surface area analysis using BET (Brunauer-Emmett-Teller) and SEM EDX (Scanning Electron Microscopy-Energy Dispersive X-Ray Spectroscopy). Based on the study results, OP has a microporous skin structure and OP-CTAB mesopores. Based on the effect of contact time, it is known that the best adsorption process on MB was to use OP adsorbent with the optimum amount of dye adsorbed produced at 50th minute that was $5.881 \mathrm{ppm}$, while the best adsorption process on MO was using OP-CTAB adsorbent with the optimum amount of dye was at 50th that was equal to $13.34 \mathrm{ppm}$. Based on the adsorption kinetics data, the adsorption of $\mathrm{MO}$ and MB dyes by OP and OP-CTAB followed the pseudo second order reaction kinetics model. The adsorption of MO and MB by both $\mathrm{OP}$ and $\mathrm{OP}-\mathrm{CTAB}$ followed Langmuir's adsorption isotherm, meaning that the adsorption process in both $\mathrm{MO}$ and $\mathrm{MB}$ using $\mathrm{OP}$ and $\mathrm{OP}-\mathrm{CTAB}$ appeared on homogeneous surface sites, while there was no interaction between adsorbate molecules and adjacent locations that means the adsorption process only occurred physically.

Keywords: CTAB-modified Orange Peel, Orange Peel, Methylene Blue, Methyl Orange.

Submitted: October 01, 2021. Accepted: January 18, 2022.

Cite this: Rosanti AD, Kusumawati Y, Hidayat F, Fadlan A, Wardani ARK, Agusyanti HA. Adsorption of Methylene Blue and Methyl Orange from Aqueous Solution using Orange Peel and CTAB-Modified Orange Peel. JOTCSA. 2022;9(1):237-46.

DOI: https://doi.org/10.18596/jotcsa.1003132.

*Corresponding author. E-mail: aulia.dewi.r@uniska-kediri.ac.id.

\section{INTRODUCTION}

Dyes have been used in various industrial sectors, especially in the textile, rubber, plastic, leather, cosmetics, food, and medicine industries. Dye waste from these industries can cause dangerous environmental problems. This is because some dyes have toxic, carcinogenic, and mutagenic properties (1,
2). Dyes used in the industrial sector, especially textiles, include methyl orange and methylene blue (1-3). Methyl orange and methylene blue are azo dyes that are nonbiodegradable, making them very difficult to degrade (3-5).

Several methods have been used to remove dye waste, including coagulation, complexation, ion 
exchange, and adsorption (6). Adsorption is not only used to remove toxic metal ions from water but also can be used to remove dyes from water $(7,8)$. Adsorption is the most commonly used method to remove azo dyes because it is relatively easy, efficient, inexpensive, and environmentally friendly. The use of biomass as a cheap and environmentally friendly adsorbent has begun to be considered as a replacement for commercially activated carbon (9). One of the potential biomass adsorbents is orange peel, and currently, the total area of citrus plantations in Indonesia is more than 57,000 hectares with a production of 2.5 million tons (10). Orange peel (OP) contains pectin, hemicellulose, lignin, chlorophyll, and other low molecular weight hydrocarbons. Thus, orange peel has the potential to absorb color from diluted solutions as an adsorbent (11).

Some studies have shown the use of orange peel as an adsorbent, including Krisnan and George (2), who found that the higher the adsorbent dose of orange peel is, the greater the amount of methylene blue that can be removed. This study showed that 2.2 grams of orange peel can remove $96 \%$ of methylene blue in 60 minutes. Nascimento et al. in 2014 (12) also reported that orange peel successfully removed Remazol Golden Yellow RNL-150\%, Reactive Gray BF$2 \mathrm{R}$ and Reactive Turquoise Q-G125 from diluted solution. The other previous studies about the use of orange peel for dye adsorption can be seen in Table 1 .

Table 1: Previous studies about the use of orange peel for dye adsorption.

\begin{tabular}{lcc}
\hline \multicolumn{1}{c}{ Dye name } & Max adsorption $\mathbf{( m g / g )}$ & References \\
\hline Congo red & 22.44 & $(13)$ \\
Procion orange & 1.33 & $(13)$ \\
Rhodamine B & 3.23 & $(13)$ \\
Acid violet 17 & 19.88 & $(14)$ \\
DR 23 & 10.72 & $(15)$ \\
DR 80 & 21.05 & $(15)$ \\
\hline
\end{tabular}

Some studies have also suggested that modifying orange peel adsorbents can maximize the adsorption process, including Ahmed et al. in 2012 (1), who successfully removed Reactive Blue 19 using orange peel and $\mathrm{NaOH}-$ and cetyltrimethylammonium bromide (CTAB)-modified orange peel. Based on previous studies, modified orange peel is better able to cause desorption of the reactive blue 19 color than the pristine orange peel. This study aimed to remove methylene blue as a cationic dye and methyl orange as an anionic dye using orange peel and CTABmodified orange peel.

\section{EXPERIMENTAL METHODS}

\section{Materials}

The materials used in this study included orange peel (orange peel was obtained from a local fruit field in northern Sumatra, Indonesia), CTAB (synthesis grade, Merck), methylene blue (Merck), methyl orange (Merck) and Aqua DM (Bratachem).

\section{Adsorbent Preparation}

Orange peels were obtained from a local fruit field in North Sumatra, Indonesia. The preparation of the adsorbent was adapted from the method of Arami et al. (2005) (15) with modification. The OP were washed several times with water and sun-dried for 2 days. The dried materials were mashed and sieved through a 60-mesh sieve. The dried powder from the orange peels was stored in a plastic container before use.

\section{CTAB Modification of Adsorbent}

CTAB modification of the adsorbent was adapted from the method of Taghried and Mayasa (2019), (16) with modification. The orange peel powder ( 5 grams) was soaked in $1 \%(\mathrm{w} / \mathrm{v})$ CTAB solution $(100 \mathrm{~mL})$ for 24 hours and filtered through a vacuum $(17,18)$. The obtained precipitate was dried in an oven at $75^{\circ} \mathrm{C}$ for 8 hours. The CTAB-modified dried powder was ground and sieved using a 60-mesh sieve.

\section{Characterization of the Adsorbents}

Fourier transform infrared spectroscopy (FTIR, Nicolet Avatar 360 IR) in the range of $400-4000 \mathrm{~cm}^{-1}$ was utilized for surface chemical analysis. The surface morphology of the adsorbents was analyzed by using scanning electron microscopy-energy dispersive X-ray spectroscopy (SEM EDX) (Phenom Desktop ProXL). The specific surface area of the adsorbents was measured by a BET $\mathrm{N}_{2}$ surface area analyzer (Quantachrome Quadrasorb Evo QDS-MP 30).

\section{MB and MO Adsorption Batch Study}

In each adsorption experiment, $25 \mathrm{~mL}$ of dye solution was added to $20 \mathrm{mg}$ of adsorbent at room temperature, and the mixture was stirred at $400 \mathrm{rpm}$ for 1 hour. The mixture was centrifuged at $3000 \mathrm{rpm}$ for 10 minutes to separate the adsorbents, and then, it was observed at wavelengths of $664.5 \mathrm{~nm}$ for $\mathrm{MB}$ and $465 \mathrm{~nm}$ for MO using a UV-Vis spectrophotometer (T70 UV-Vis Spectrophotometer, PG Instrument Ltd). The amount of MB/MO adsorbed by OP and OP-CTAB at time $t, q_{t}(\mathrm{mg} / \mathrm{g})$, was calculated by Equation (1) (1): 


$$
q_{t}=\frac{\left(C_{0}-C_{t}\right) V}{w}
$$

The MB/MO percentage of adsorption was calculated by Equation (2) (1):

$$
\% \text { Removal }=\frac{\left(C_{0}-C_{t}\right)}{C_{0}} \times 100
$$

\section{RESULTS AND DISCUSSION}

\section{FTIR Analysis}

FTIR spectroscopy is a useful analytical instrument for the identification of the functional groups in the adsorbents and the interaction of orange peels with CTAB. The FTIR spectra of CTAB, OP and OP-CTAB were in the range of $400-4000 \mathrm{~cm}^{-1}$, as shown in Figure 1. The FTIR spectra of CTAB showed sharp peaks in the absorption bands at approximately 2918.41 and $2848.08 \mathrm{~cm}^{-1}$ due to the symmetrical and asymmetrical stretching vibrations of the $\mathrm{CH}_{2}$ group on CTAB (19-23). In addition, there was a peak at $1479.87 \mathrm{~cm}^{-1}$ for the buckling vibration of the $\mathrm{N}-\mathrm{C}$ group on CTAB (24).

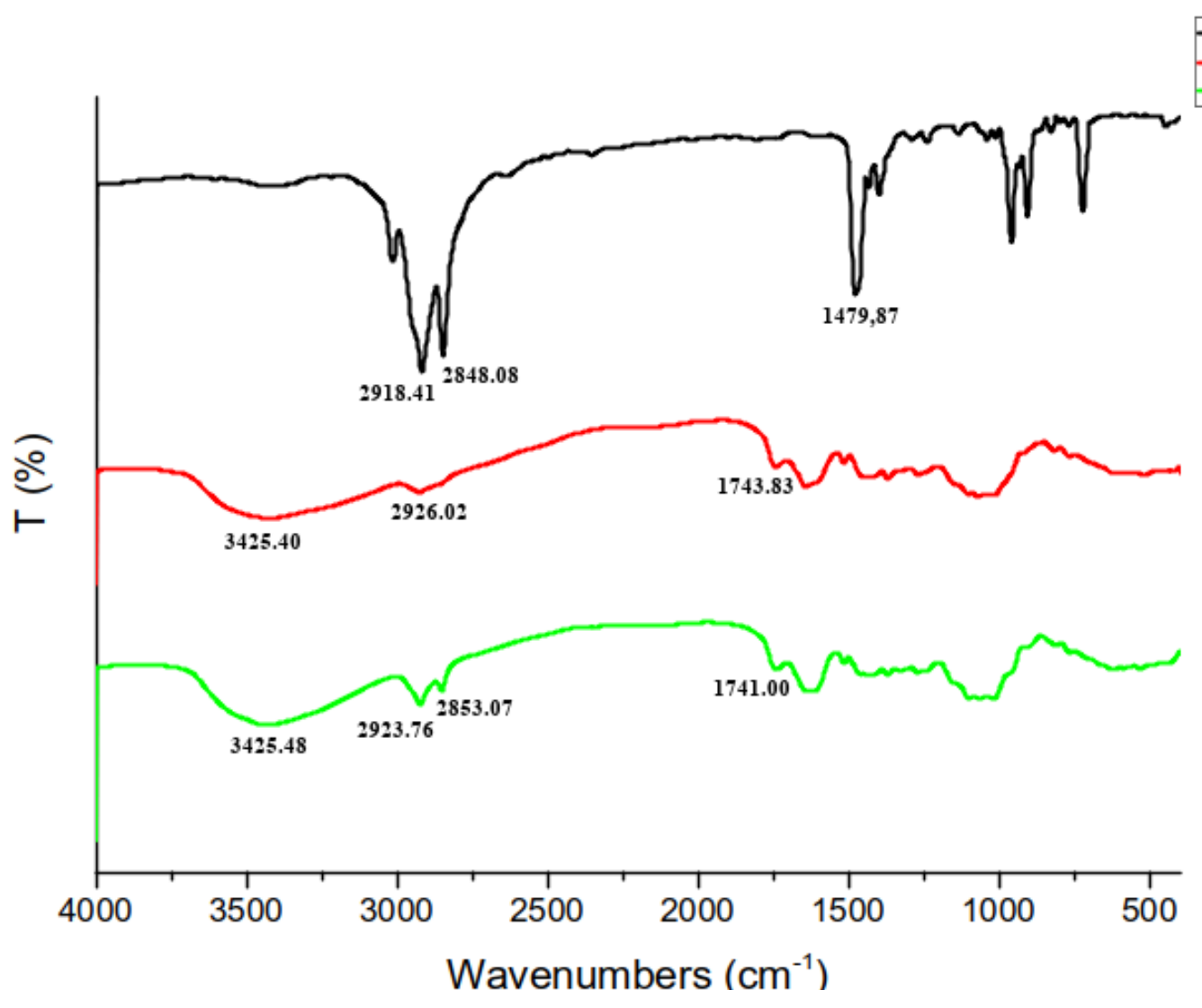

Figure 1: IR spectra of $C T A B, O P$, and OP-CTAB.

In the OP's spectra, the absorption widened at $3425.40 \mathrm{~cm}^{-1}$, indicating the presence of stretching vibrations from the $-\mathrm{OH}$ groups of cellulose, pectin, hemicellulose, and lignin. The peak at $2926.02 \mathrm{~cm}^{-1}$ was due to the $\mathrm{C}-\mathrm{H}$ stretching vibrations. The 1743.83 $\mathrm{cm}^{-1}$ peak in the OP's spectra indicated the stretching vibrations of the carbonyl groups $(\mathrm{C}=\mathrm{O})$ of pectin, hemicellulose, and lignin. The absorption band was in the wavenumber range of $1300-1000 \mathrm{~cm}^{-1}$ for the C-O stretching vibration of the carboxylic acid and alcohol groups $(25,26)$.

The FTIR spectra of OP-CTAB showed similarities with the FTIR spectra of OP, indicating that both have similar functional groups and almost the same compounds. The peak intensity in the FTIR spectra of OP at $2926 \mathrm{~cm}^{-1}$ increased from 26.12 to 38.48 (34.22\%) after modification with CTAB. This indicates 
that $C T A B$ modification in orange peel increases the number of $-\mathrm{CH}_{2}-$ groups (1). In addition, the modification of the orange peel by CTAB is also shown by two peaks at wavenumbers of approximately 2923.76 and $2853.07 \mathrm{~cm}^{-1}$ in the FTIR spectra of OP$C T A B$ as the peak from the symmetrical and asymmetrical stretching vibration of the $\mathrm{C}-\mathrm{H}$ group of $\operatorname{CTAB}(19,23)$.

\section{Characterization of OP Powder and OP-CTAB using BET}

BET analysis determines the surface area and pore size, while the BJH (Barrett-Joiner-Halenda) method is used to determine the pore volume. In Table 2, the surface area of OP is larger than OP-CTAB. OP has a surface area of $204 \mathrm{~m}^{2} / \mathrm{g}$, and OP-CTAB has a surface area of $27.210 \mathrm{~m}^{2} / \mathrm{g}$. Based on these results, the $C T A B$ modification of OP resulted in a smaller surface area than OP. Although the surface area in OP is larger, OP has a smaller pore size of $1.780 \mathrm{~nm}$, while $O P-C T A B$ has a smaller pore size of $2.045 \mathrm{~nm}$.

Table 2: BET Analysis Results for OP and OP-CTAB.

\begin{tabular}{lccc}
\hline Biomass & Surface Area $\left(\mathbf{m}^{\mathbf{2}} \mathbf{/ g}\right)$ & Pore Volume & Pore size $(\mathbf{n m})$ \\
\hline OP & 204.000 & 0.181 & 1.780 \\
OP-CTAB & 27.210 & 0.028 & 2.045 \\
\hline
\end{tabular}

Based on the pore size, a porous material can be classified into three classes, namely, microporous material (pore size $<2 \mathrm{~nm}$ ), mesopores (pore size 2-50 $\mathrm{nm}$ ) and macropores (pore size $>50 \mathrm{~nm}$ ) (27). OP has a pore size of $1.780 \mathrm{~nm}$, so it can be categorized as a microporous material, while OP-CTAB has a pore size of $2.045 \mathrm{~nm}$, and it can be classified as a mesoporous material. The presence of CTAB induced the formation of mesopores that can be used for polymers and other large compounds that resulted in better particle dispersion (27). Based on the data, it can be concluded that OP has a large surface area but a microporous pore structure, while OP-CTAB has a small surface area but a mesoporous structure whereby mesopores can produce better particle dispersion than other porous structures. In contrast to the results of research from Taghried and Mayasa (2019) (16) which resulted in a larger surface area of OP-CTAB than OP. This is because in this research the character of orange peel is more porous and it can be seen from the high surface area before the addition of $C T A B$, so that the CTAB enters the pores, whereas in the previous research it may be less porous, as can be seen from the very low BET result.

\section{Characterization of OP Powder and OP-CTAB using SEM EDX}

SEM EDX analysis is necessary to determine the morphology and content of elements present on the surface of OP and OP-CTAB. Figure 2 shows that the surface of $\mathrm{OP}$ is rougher and more irregular compared to the surface of OP-CTAB. In addition, the addition of CTAB made OP smaller and more separate compared to that without the addition of CTAB. This is supported by the results of $B E T$ analysis showing the pores from OP-CTAB compared to OP. According to the BET results, the OP surface area is larger than OP-CTAB, but based on pore size, OP has a microporous structure, while OP-CTAB has a mesoporous structure.
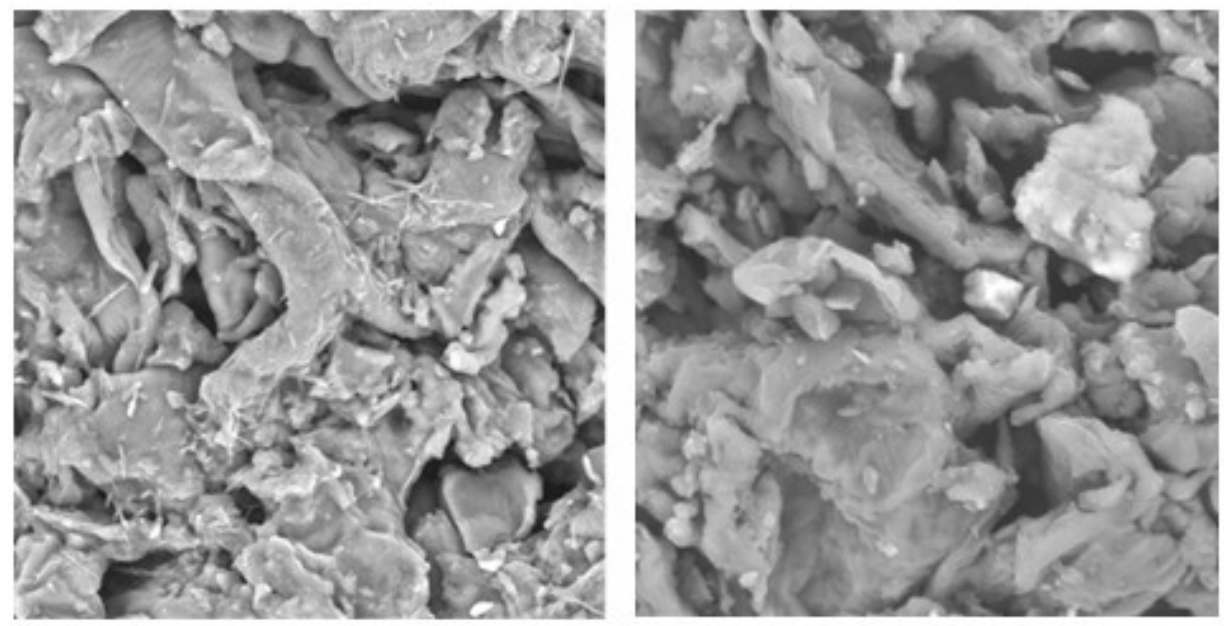

Figure 2: Surface morphologies of OP (left) OP-CTAB (right). 
In addition to showing the surface morphological results of a material, SEM EDX can be used to determine the elements present on a material surface. Based on Table 3, the surface of OP contains the elements of carbon (C), oxygen (O), calcium (Ca) and potassium (K). In comparison, OP-CTAB contains the elements of carbon (C), oxygen (O), nitrogen $(\mathrm{N})$, and aluminum (Al). Additionally, the EDX results in
Table 3 show the presence of $\mathrm{N}$ at $8.410 \%$ in OP$C T A B$, indicating that $C T A B$ successfully entered or attached to the surface of OP. The presence of the $N$ element from the ammonium group of CTAB with a positive partial charge causes OP-CTAB to have cationic properties, so it is easier to attract anionic dyes than OP.

Table 3: Total (\%) components on OP and OP-CTAB surfaces.

\begin{tabular}{cccc}
\hline Sample & Element & Mass (\%) & Atom (\%) \\
\hline \multirow{4}{*}{ OP } & $\mathrm{C}$ & 62.100 & 69.460 \\
& $\mathrm{O}$ & 35.340 & 29.680 \\
& $\mathrm{Ca}$ & 1.640 & 0.550 \\
& $\mathrm{~K}$ & 0.920 & 0.320 \\
OP-CTAB & $\mathrm{C}$ & 67.810 & 73.640 \\
& $\mathrm{O}$ & 21.200 & 17.280 \\
& $\mathrm{~N}$ & 8.410 & 7.830 \\
& $\mathrm{Al}$ & 2.590 & 1.250 \\
\cline { 2 - 4 } & & &
\end{tabular}

\section{Contact Time Effect}

Figure 3 shows the percentage of $M O$ and $M B$ adsorbed by OP and OP-CTAB at room temperature at $25^{\circ} \mathrm{C}$ as a function of contact time. The variation in contact time was 10, 20, 30, 40, 50 and 60 minutes at $15 \mathrm{mg} / \mathrm{L} \mathrm{MO}$ and $\mathrm{MB}$.
Based on Figure 3, the best color removal rate was for the OP-CTAB adsorbent on MO and for OP on MB. Thus, OP-CTAB was more effectively used to remove MO dyes than MB dyes, while OP was more effectively used to remove MB dyes than MO dyes. The amount of MB and MO that can be adsorbed using OP and OPCTAB in ppm can be see Figure 4.

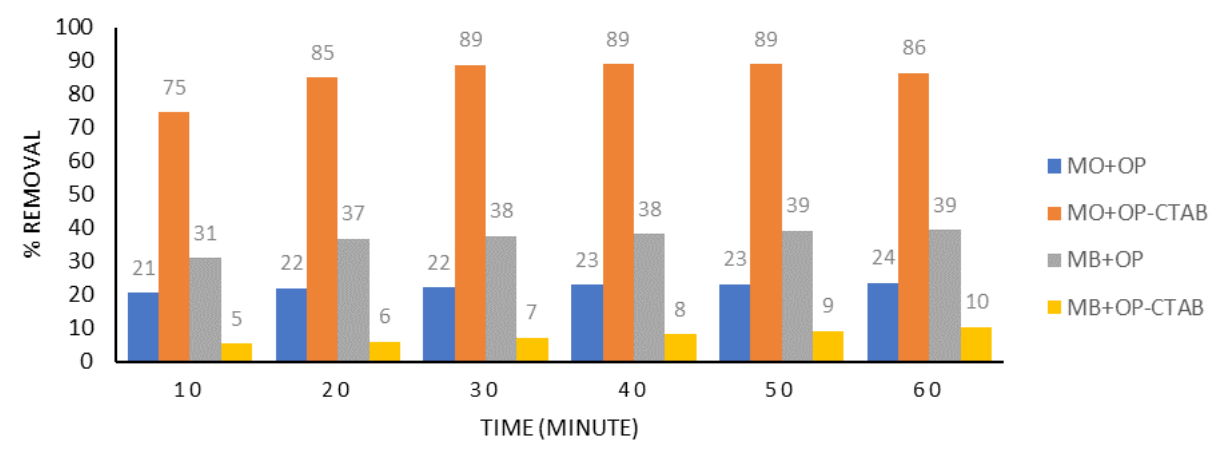

Figure 3: Relationship between Adsorption Capacity and Contact Time.
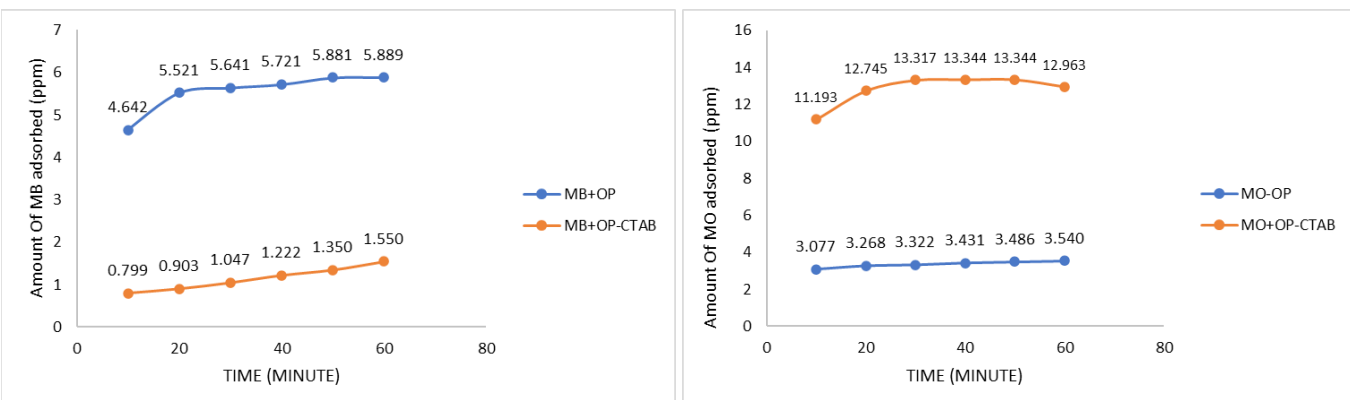

Figure 4: Amount of adsorbed dye vs. Contact Time MB 15 ppm (left); MO 15 ppm (right). 
Based on Figure 4, it is known that the amount of $M B$ that was successfully adsorbed using the OP adsorbent for 60 minutes was $5.889 \mathrm{ppm}$ (39\%), while MO was only able to adsorb $3.540 \mathrm{ppm}(24 \%)$. Different with OP-CTAB adsorbent, the amount of MB that was successfully absorbed at $60^{\text {th }}$ minute on $M B$ was $1.550 \mathrm{ppm}$ (10\%) while in MO it was $12.963 \mathrm{ppm}$ $(86 \%)$. Based on the results can be concluded that OP is better used to adsorb MB dye than MO and OPCTAB is a better adsorption agent for MO than for MB. $O P$ contains cellulose, pectin, hemicellulose, lignin and other compounds. The pectin compound in OP has a carboxylic acid group that causes OP to be negatively charged so that it is easier to absorb cationic dyes. OP-CTAB was more effective at absorbing anionic dyes due to $\mathrm{N}^{+}$derived from the ammonium group, causing OP-CTAB to have more cationic properties than OP. This is supported by the SEM EDX data showing the $N$ content in OP-CTAB; thus, CTAB has successfully entered the OP surface. Cellulosic hydroxyl groups from OP combined with the cationic surfactant (CTAB) will form an ester linkage and present $-\mathrm{CH}_{2}-$ groups to the fiber, leading to a columbic attraction between the cationic cellulose and the anionic dyes (MO) (1).

Based on Figure 4, it can be seen that the optimum condition of MB adsorption was by using OP that occurs at $50^{\text {th }}$ minute was $5.881 \mathrm{ppm}$. Meanwhile, the optimum condition for MO occurred using OP-CTAB adsorbent at $50^{\text {th }}$ minute that was $13.344 \mathrm{ppm}$. The use of OP-CTAB on MB and OP on MO had not reached optimal adsorption, it can be seen from the trend of the linear line tends to be gentle on MB-OP adsorption and tends to decrease for MO-OP-CTAB at $50^{\text {th }}$ and $60^{\text {th }}$ minute. It is due to the fact that at the minute the adsorption process had reached the equilibrium between the adsorbent and the adsorbate and reached the saturation limit, so that the adsorption reached the optimum. In contrast with MB-OP-CTAB and MO-OP adsorption processes, the adsorption process can be seen in the graph that the trend line tends to rise that indicates the adsorption process had not yet reached the optimum. Based on the description above, it can be seen that the best adsorption process on $\mathrm{MB}$ was using $\mathrm{OP}$ adsorbent with the optimum amount of dye adsorbed produced at $50^{\text {th }}$ minute that was $5.881 \mathrm{ppm}$, while the best adsorption process on MO was using OP-CTAB adsorbent with the optimum amount of dye was at $50^{\text {th }}$ minute that was equal to $13.34 \mathrm{ppm}$.

\section{Adsorption Kinetics}

The determination of the reaction order from the adsorption process and reaction rate constants can be analyzed using pseudo first order or pseudo second order reaction kinetics equations. The kinetics of pseudo first order adsorption is based on mass equilibrium assuming that the rate between successful absorption and the time is proportional to the compensation of the dye absorbed at various times $\left(\mathrm{q}_{\mathrm{e}}-\mathrm{q}_{\mathrm{t}}\right)$. Thus, it can be formulated using the following equation:

$$
\ln \left(q_{e}-q_{t}\right)=\ln q_{e}-k_{1} t
$$

where $\mathrm{q}_{\mathrm{e}}$ is the concentration of adsorbate at equilibrium, $\mathrm{q}_{t}$ is the concentration of adsorbate at time $t, t$ is the contact time (minutes) and $k_{1}$ is the constant rate it adsorbs. At time $\mathrm{t}=0$, then $\mathrm{q}_{\mathrm{t}}=0$, and at time $t=t$, then $q_{t}=q_{t}$. The value can be obtained by plotting $\ln \left(q_{e}-q_{t}\right)$ versus $t$ (Figure $5(a)$ ). Meanwhile, the pseudo second order, which can also be referred to as pseudo chemical reactions, is described in Equation 4. The $k_{2}$ or pseudo second order reaction rate constant is obtained by plotting a graph of t/qt vs. $t$ (Figure $5(b)$ ). The results of $R^{2}$ regression values and reaction rate constants on each reaction kinetics model are shown in Table 4.

$$
\frac{t}{q_{t}}=\frac{1}{k_{2} q_{e}^{2}}+\frac{1}{q_{e}} t
$$

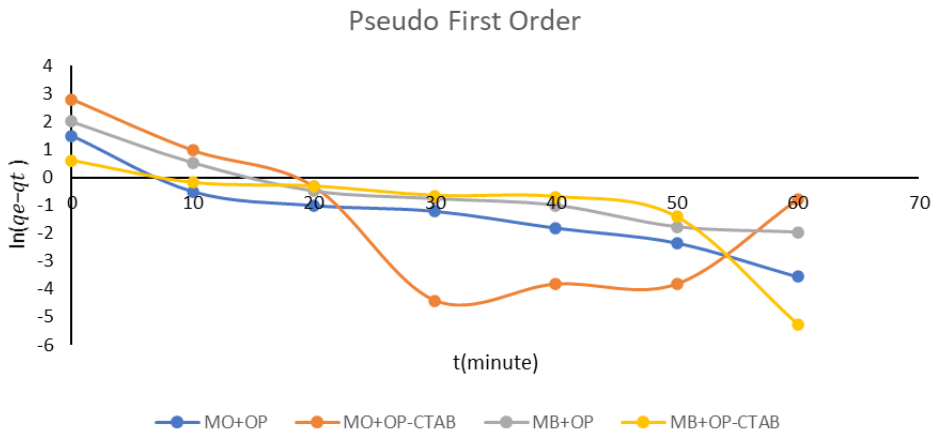




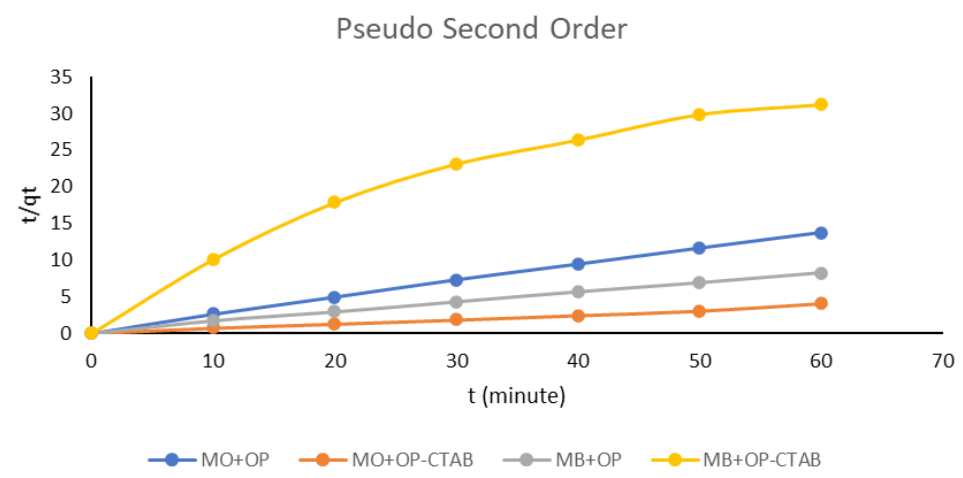

Figure 5: Adsorption Kinetics Pseudo first order (top) and Pseudo second order (bottom) from MO+OP; $\mathrm{MO}+\mathrm{OP}-\mathrm{CTAB} ; \mathrm{MB}+\mathrm{OP}$ and $\mathrm{MB}+\mathrm{OP}-\mathrm{CTAB}$.

Based on Table 4, the linear regression value $\left(R^{2}\right)$ of the pseudo second order model was greater than the $\mathrm{R}^{2}$ value of the pseudo first order model. This proves that the adsorption of $\mathrm{MO}$ and $\mathrm{MB}$ dyes by OP and OP$C T A B$ followed the pseudo second order reaction kinetics model.

Table 4: Constants of the reaction rate and linear regression for pseudo first order and pseudo second order kinetics.

\begin{tabular}{lllll}
\hline Sample & $\mathbf{k}_{\mathbf{1}}$ & $\mathbf{R}^{\mathbf{2}}$ & $\mathbf{k}_{\mathbf{2}}$ & $\mathbf{R}^{\mathbf{2}}$ \\
\hline MO+OP & 0.069 & 0.919 & 0.184 & 0.999 \\
MO+OP-CTAB & 0.030 & 0.209 & 0.388 & 0.996 \\
MB+OP & 0.050 & 0.869 & 0.085 & 0.998 \\
MB+OP-CTAB & 0.073 & 0.673 & 0.055 & 0.924 \\
\hline
\end{tabular}

Table 4 shows that the reaction rate constant of $\mathrm{MO}+\mathrm{OP}-\mathrm{CTAB}$ was greater than that of MO+OP, indicating that adsorption reactions using OP-CTAB in anionic dyes were faster than those using OP. In cationic dyes, the adsorption reaction rate constant of $\mathrm{OP}$ was greater than that of OP-CTAB, confirming that in cationic dyes, OP is more effective than OP-CTAB.

\section{Adsorption Isotherm}

The adsorption isotherm expresses the relationship between the adsorbate concentration and adsorption capacity at equilibrium and a fixed temperature (15). Adsorption isotherms are often used to characterize heavy metal adsorption, dyes, volatile organic compounds, and gases (28). Adsorption isotherm models can also provide information on the maximum adsorption capacity, which is significant in the evaluation of adsorbent performance (29). According to Langmuir's assumption, there are five adsorption processes where the chemisorption mechanism dominates while the shape of the adsorbate molecule is a single layer or monolayer. In addition, there is no interaction between the adsorbed molecules, and the affinity of the adsorbate molecule is the same for each place on the surface of a homogeneous solid with the adsorbent molecule at a specific location. It does not transfer to the concrete surface and is always irreversible (30). Langmuir's equation can be written as follows $(15,29)$ :

$$
\frac{C_{e}}{q_{e}}=\frac{1}{k_{L}} q_{\max }+\frac{1}{q_{\max }} C_{e}
$$

$\mathrm{C}_{\mathrm{e}}$ is the concentration of dissolved substances at the time of equilibrium ( $\mathrm{mg} / \mathrm{L}), \mathrm{q}_{\mathrm{e}}$ is the quantity of dyes absorbed at the time of equilibrium $(\mathrm{mg} / \mathrm{g}), q_{\max }$ is the maximum adsorption capacity, and $\mathrm{k}$ is the ratio of the adsorption rate and desorption rate. $\mathrm{Q}_{\max }$ and $\mathrm{k} \mathrm{L}$ values can be determined from the intercept and slope on the linear curve of the relationship of $\mathrm{C}_{e} / \mathrm{Q}_{e}$ vs. $C_{e}$ (Figure. 6). 


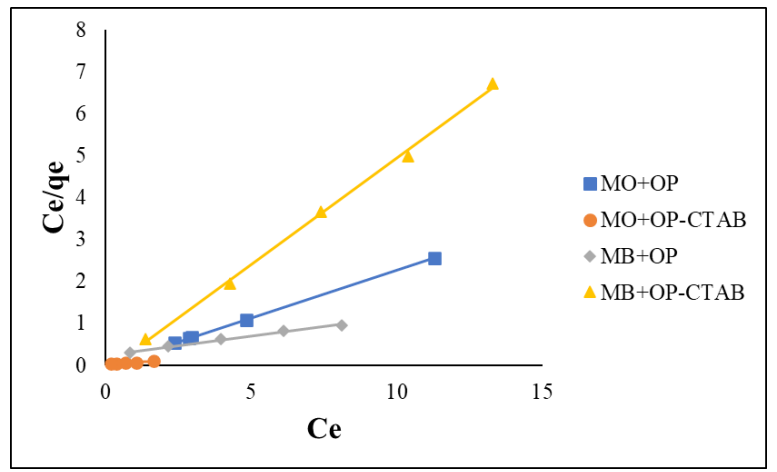

Figure 6: Langmuir Isotherm Plot.

Freundlich's model shows that the equilibrium relationship in adsorption can be explained by the absence of molecular separation on the surface after absorption and the lack of chemical adsorption events. The Freundlich equation occurs only in fissile adsorption events due to the absence of molecular configuration exchanges in the adsorption process. The molecular form of the adsorbate in this process of the adsorption isotherm is a multilayer (30). The Freundlich equation can be written as follows:

$$
\log q_{e}=\log k_{f}+\frac{1}{n} \log C_{e}
$$

$\mathrm{k}_{\mathrm{f}}$ is the Freundlich constant that represents the adsorption capacity at the time of equilibrium, and $1 / n$ is the intensity of the adsorption. The values of $k_{f}$ and $1 / \mathrm{n}$ can be determined through the intercept and slope of the linear curve of the relationship of $\log q_{e}$ vs. $\log C_{e}$ (Figure. 7).

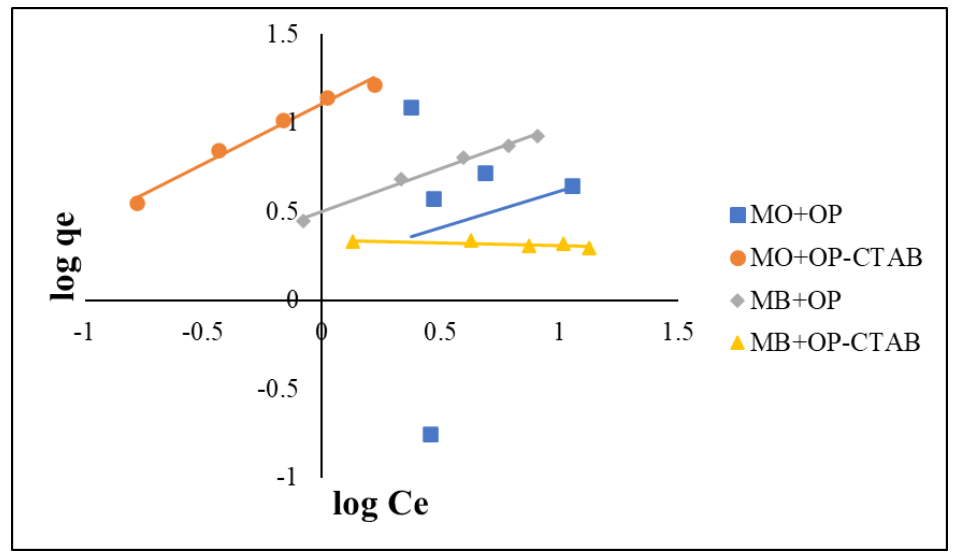

Figure 7: Freundlich Isotherm Plot.

In Figure 7, it is shown that both $\mathrm{OP}$ and $\mathrm{OP}-\mathrm{CTAB}$ adsorption isotherms on $M O$ and $M B$ followed Langmuir's adsorption isotherm. This is evidenced by the linearity value $\left(R^{2}\right)$ of Langmuir's adsorption isotherm being greater than that of the Freundlich adsorption isotherms (Table 5). Based on these results, it can be concluded that the adsorption process in $\mathrm{MO}$ and $\mathrm{MB}$ using $\mathrm{OP}$ and OP-CTAB occurred on homogeneous surfaces, while there was no interaction between adsorbate molecules and adjacent areas that means the adsorption process only occurs physically. Table 5 indicates that the highest maximum adsorption capacity $\left(q_{\max }\right)$ was 27.780 , i.e., in the MO adsorption process by OP$C T A B$. This suggests that the addition of CTAB can help the adsorption process more maximally with the adsorption of anionic dyes. For the removal of cationic dyes, the use of orange peel without CTAB was better than orange peel with CTAB. This result is proven by the adsorption capacity, in which the MB adsorption process by OP was more significant than the adsorption capacity for removing MB by OP-CTAB. 
Table 5: Constants and $\mathrm{R}^{2}$ values of the Langmuir and Freundlich isotherm models.

\begin{tabular}{lcccccc}
\hline \multirow{2}{*}{ Sample } & \multicolumn{3}{c}{ Langmuir Isotherm } & \multicolumn{3}{c}{ Freundlich Isotherm } \\
\cline { 2 - 7 } & $\mathbf{k}$ & $\mathbf{q}$ max & $\mathbf{R}^{\mathbf{2}}$ & $\mathbf{k}_{\mathbf{F}}$ & $\mathbf{1 / n}$ & $\mathbf{R}^{\mathbf{2}}$ \\
\hline MO+OP & $5.50 \times 10^{15}$ & 4.405 & 1.000 & 1.609 & 0.409 & 0.025 \\
MO+OP-CTAB & 696.180 & 27.778 & 0.995 & 12.840 & 0.680 & 0.984 \\
MB+OP & 44.800 & 10.960 & 0.993 & 3.160 & 0.480 & 0.992 \\
MB+OP-CTAB & -14.780 & 1.970 & 0.998 & 2.190 & -0.030 & 0.498 \\
\hline
\end{tabular}

\section{CONCLUSION}

Based on previous studies, based on the pore size, OP has a microporous structure, while OP-CTAB has a mesoporous structure. The best adsorption process on MB was using OP adsorbent with the optimum amount of dye adsorbed produced at $50^{\text {th }}$ minute that was $5.881 \mathrm{ppm}$, while the best adsorption process on $\mathrm{MO}$ was to use adsorbent OP-CTAB with the optimum amount of the best dye was at $50^{\text {th }}$ minute that was equal to $13.34 \mathrm{ppm}$. So, the use of OP-CTAB biomass is better for removing anionic dyes, while OP is better used to remove cationic dyes due to the $\mathrm{N}$ element from the ammonium group of CTAB because this group has a positive partial charge causing OP-CTAB to have cationic properties so it is easier to attract anionic dyes than OP. Based on the kinetics adsorption, the adsorption of MO and MB dyes by OP and OP-CTAB followed the pseudo second order kinetic reaction model. The adsorption of $M O$ and $M B$ by OP and OP-CTAB followed the Langmuir adsorption isotherm, meaning that the adsorption process in $M O$ and $M B$ using $O P$ and OP-CTAB appeared on homogeneous surface sites, while there was no interaction between adsorbate molecules and adjacent sites that means the adsorption process only occurs physically.

\section{ACKNOWLEDGEMENTS}

The authors gratefully acknowledge the Indonesian Ministry Education, Culture, Research and Technology for financial support for this research and Universitas Islam Kadiri for the facilities.

\section{CONFLICT OF INTEREST STATEMENT}

The authors declare no conflicts of interest for this article.

\section{REFERENCES}

1. Sayed Ahmed SA, Khalil LB, El-Nabarawy T. Removal of Reactive Blue 19 dye from Aqueous Solution Using Natural and Modified Orange Peel. Carbon letters. 2012 Ekim;13(4):212-20. <DOI.
2. Krishnan A, George D. Methylene blue removal using orange peel. International Journal of Scientific \& Engineering Research. 2016;7(4):250-2.

3. Yuningrat NW, Retug N, Gunamantha IM. Fotodegradasi Methyl Orange Dalam Reaktor Fixed Bed Batu Apung-Semen. J Sains Teknologi [Internet]. 2016 Aug 5;5(1): 692-701. <DOI $>$.

4. Cristina PM, Mu'nisatun S, Saptaaji R. Studi Pendahuluan Mengenai Degradasi Zat Warna Azo (Metil Orange) Dalam Pelarut Air Menggunakan Mesin Berkas Elektron $350 \mathrm{keV} / 10 \mathrm{~mA}$. Jurnal Forum Nuklir. 2007 May $1 ; 1(1): 31$.

5. Huda T, Yulitaningtyas TK. Kajian Adsorpsi Methylene Blue Menggunakan Selulosa dari AlangAlang. Ind J Chem Anal [Internet]. 2018 Sep 20 [cited 2022 Jan 21];1(01): 9-19. <DOI>.

6. Yulianti Z, Munasir. Nanopartikel $\mathrm{Fe}_{3} \mathrm{O}_{4} / \mathrm{SiO}_{2}$ Berbasis Bahan Alam Sebagai Material Pengadsorpsi Pewarna dalam Air. J Inov Fis Indones. 2020;9(1):14.

7. Nandi R, Laskar S, Saha B. Surfactant-promoted enhancement in bioremediation of hexavalent chromium to trivalent chromium by naturally occurring wall algae. Res Chem Intermed. 2017 Mar;43(3):1619-34. <DOI $>$.

8. Mukherjee K, Saha R, Ghosh A, Ghosh SK, Maji PK, Saha B. Surfactant-assisted bioremediation of hexavalent chromium by use of an aqueous extract of sugarcane bagasse. Res Chem Intermed. 2014 Apr;40(4):1727-34. <DOI $>$.

9. Rahadi B, Robbaniyah A, Pertanian T, Brawijaya U, Veteran J. Analysis of Methyl Orange Concentration Reduction Using Musa Acuminata Cv. Cavendish Banana Peel as Biosorbent. J Sumberd Alam dan Linkungan. 2019;6(2):29-35.

10. Hanif Z. Pengembangan Agribisnis Jeruk Nusantara. Iptek Hortikultura. 2020;16-N(Gambar 2):27-30.

11. Munagapati VS, Kim D-S. Adsorption of anionic azo dye Congo Red from aqueous solution by Cationic 
Modified Orange Peel Powder. Journal of Molecular Liquids. 2016 Aug;220:540-8. <DOI>.

12. do Nascimento GE, Duarte MMMB, Campos NF, Rocha ORS da, Silva VL da. Adsorption of azo dyes using peanut hull and orange peel: a comparative study. Environmental Technology. 2014 Jun 3;35(11):1436-53. <DOI $>$.

13. Namasivayam C, Muniasamy N, Gayatri K, Rani M, Ranganathan K. Removal of dyes from aqueous solutions by cellulosic waste orange peel. Bioresource Technology. 1996 Jul;57(1):37-43. <DOI>.

14. Sivaraj R, Namasivayam C, Kadirvelu K. Orange peel as an adsorbent in the removal of Acid violet 17 (acid dye) from aqueous solutions. Waste Management. 2001;21(1):105-10. <DOI >.

15. Arami M, Limaee NY, Mahmoodi NM, Tabrizi NS. Removal of dyes from colored textile wastewater by orange peel adsorbent: Equilibrium and kinetic studies. Journal of Colloid and Interface Science. 2005 Aug;288(2):371-6. $\leq \mathrm{DOI}>$.

16. Salman T, Ali M. Eriochrome Black $T$ dye adsorption onto natural and modified orange peel. Res J Chem Environ. 2019;23(1):155-69.

17. Ansari R, Seyghali B, Mohammad-khah A, Zanjanchi MA. Highly Efficient Adsorption of Anionic Dyes from Aqueous Solutions Using Sawdust Modified by Cationic Surfactant of Cetyltrimethylammonium Bromide. J Surfact Deterg. 2012 Sep;15(5):557-65. $\leq \mathrm{DOI}>$.

18. Mohamed Pauzan AS, Ahad N. Biomass Modification Using Cationic Surfactant Cetyltrimethylammonium Bromide (CTAB) to Remove Palm-Based Cooking Oil. Journal of Chemistry. 2018 Dec 24;2018:1-7. <DOI>.

19. Ai F, Zhao G, Lv W, Lin J. Facile synthesis of cetyltrimethylammonium bromide-loaded mesoporous silica nanoparticles for efficient inhibition of hepatocellular carcinoma cell proliferation. Materials Research Express. 2020 Aug;7(8):085008. <DOI>.

20. del Caño R, Gisbert-González JM, GonzálezRodríguez J, Sánchez-Obrero G, Madueño R, Blázquez $M$, et al. Effective replacement of cetyltrimethylammonium bromide (CTAB) by mercaptoalkanoic acids on gold nanorod (AuNR) surfaces in aqueous solutions. Nanoscale. 2020;12(2):658-68. <DOI $>$.

21. Che Ismail NH, Ahmad Bakhtiar NSA, Md. Akil H. Effects of cetyltrimethylammonium bromide (CTAB) on the structural characteristic of non-expandable muscovite. Materials Chemistry and Physics. 2017 Aug;196:324-32. <DOI . 
22. Campbell RA, Parker SRW, Day JPR, Bain CD. External Reflection FTIR Spectroscopy of the Cationic Surfactant Hexadecyltrimethylammonium Bromide (CTAB) on an Overflowing Cylinder. Langmuir. 2004 Sep 1;20(20):8740-53. <DOI>.

23. Azmiyawati C, Sawitri E, Siahaan P, Darmawan A, Suyati L. Preparation of magnetite-silicacetyltrimethylammonium for phenol removal based on adsolubilization. Open Chemistry. 2020 Apr 21;18(1):369-76. <DOI $>$.

24. Febiyanti IA, Suseno A, Priyono P. Pengaruh Konsentrasi Surfaktan

CTAB

(Cetyltrimethylammonium bromide) pada Modifikasi Lempung dengan Oksida Besi sebagai Pemilar. J Kim Sains Apl. 2013 Dec 1;16(3):79-83. <DOI>.

25. Feng N, Guo X, Liang S. Adsorption study of copper (II) by chemically modified orange peel. Journal of Hazardous Materials. 2009 May 30;164(23):1286-92. <DOI $>$.
26. Anas NAA, Fen YW, Yusof NA, Omar NAS, Ramdzan NSM, Daniyal WMEMM. Investigating the Properties of Cetyltrimethylammonium Bromide/Hydroxylated Graphene Quantum Dots Thin Film for Potential Optical Detection of Heavy Metal Ions. Materials. 2020 Jun 6;13(11):2591. <DOI>.

27. Purbaningtias TE, Kurniawati $P$, Wiyantoko $B$, Prasetyoko D, Suprapto S. Pengaruh Waktu Aging Pada Modifikasi Pori Zeolit Alam Dengan Ctabr. J Sains Teknologi. 2017 Nov 27;6(2):321. <DOI>.

28. Badriyah L, Putri M. Kinetika Adsorpsi Cangkang Telur pada Zat Warna Metilen Biru. Alchemy. 2017;5(3):85-91.

29. Wang J, Guo X. Adsorption isotherm models: Classification, physical meaning, application and solving method. Chemosphere. 2020 Nov;258:127279. $\leq$ DOI $>$.

30. Fadli A, Komalasari M, Amir D, Sari, Siburian R. Model Kesetimbangan Adsorpsi $\mathrm{Zn}+2$ dengan Kaolin. Reaktor. 2004;8(2):59-62. 